\begin{tabular}{c|c|c}
\hline \hline Vol. 28: 13-19, 2019 & AQUATIC BIOLOGY \\
Aquat Biol & Published January 10 \\
\hline
\end{tabular}

\title{
Intersex in male invasive Atlantic lionfish, Pterois spp.
}

\author{
David G. Matthews ${ }^{1}$, James A. Morris Jr. ${ }^{2, *}$ \\ ${ }^{1}$ Department of Organismic and Evolutionary Biology, Harvard University, Cambridge, MA 02138 USA \\ ${ }^{2}$ NOAA National Centers for Coastal Ocean Science, Beaufort, NC 28516, USA
}

\begin{abstract}
Intersex in gonochoristic species is a reproductive abnormality in which an individual produces gametes of the type normally associated with the opposite sex. To investigate the prevalence of intersex in male lionfish Pterois spp., 884 individuals were collected from the Bahamas and North Carolina between 2004 and 2008. Histological sections of testes were scored for the presence or absence of oocytes. In intersex individuals, the number of oocytes, size, and developmental stage was recorded. The prevalence of intersex was approximately $15 \%$ and, along with all other measured metrics describing the condition, did not significantly differ between the 2 locations. Most of the intersex males displayed only primary-stage oocytes embedded in structurally normal gonadal tissue. However, 3 fish from the Bahamas exhibited oocytes of all developmental stages and complete restructuring of the gonadal tissue that is atypical of both male and female lionfish. This study is the first extensive report of intersex in lionfish, and the first in a gonochoristic reef fish.
\end{abstract}

KEY WORDS: Ovotestis · Intersex · Secondary oocyte $\cdot$ Endocrine disruptor $\cdot$ Invasive

\section{INTRODUCTION}

When an animal has a gonad displaying both ovarian and testicular tissue, the gonad is called intersex. There is a wide body of literature that describes the prevalence, histological appearance, and possible causes of this condition in various wild fish species (reviewed by Bahamonde et al. 2013) as well as in lab-raised and experimentally manipulated fish (Gray \& Metcalfe 1997, Gray et al. 1999, Arukwe 2001, Metcalfe et al. 2001, Imai et al. 2005). While many of these papers focused on environmental and hormonal causes, intersex is also known to happen spontaneously in relatively high prevalence (Grim et al. 2007). Intersex in fish generally manifests as oocytes in testicular tissue (Bahamonde et al. 2013), but the opposite condition has also been described (Nolan et al. 2001). Despite the diversity of species and pathologies of the disease, there are also many species that are not susceptible to intersex

${ }^{*}$ Corresponding author: james.morris@noaa.gov even in the presence of pollutants (Kavanagh et al. 2004).

One of the most ecologically damaging marine invasions in recent times has been the introduction of the lionfish Pterois volitans and P. miles. Lionfish are native to the Indo-Pacific oceans and were introduced along the southern US coast through the aquarium trade (Hare \& Whitfield 2003, Ruiz-Carus et al. 2006, Morris \& Whitfield 2009). Their biology and ecology have been the subject of a great deal of research in the past decade (Morris 2012, Gardner et al. 2015, Fogg et al. 2017); however, the only report of intersex is limited to a brief side note about a single affected individual (Fogg et al. 2017). Here, we present the first evidence of intersex in lionfish at substantial levels and the first description of the condition in the species. We also present several examples of truly intermediate intersex in which the gonad displays characteristics of both ovaries and testes. This work constitutes the first report of extensive intersex in a marine reef-dwelling species.

() The authors 2019. Open Access under Creative Commons by Attribution Licence. Use, distribution and reproduction are unrestricted. Authors and original publication must be credited. 


\section{MATERIALS AND METHODS}

\subsection{Lionfish collection and processing}

Lionfish were collected from various sites in North Carolina and the Bahamas between 2004 and 2008 during all months of the year. Collection sites ranged in depth from approximately 1-30 m. Although both species were present, we did not attempt to differentiate between Pterois volitans and P. miles, as it is assumed that they do not differ reproductively (Morris et al. 2011). All lionfish were euthanized by either lowering temperature below the level of hypothermia or applying lethal doses of MS-222 or eugenol. Gonadal tissue, either whole or excised from the center of the gonad, was preserved in 9-10\% neutral buffered formalin, rinsed in phosphate buffered saline, dehydrated through a graded ethanol series, and embedded in paraffin according to conventional histological techniques (Morris et al. 2011). Tissue sections $(5-6 \mu \mathrm{m})$ were stained with a mixture of Mayer's/ Harris hematoxylin and alcoholic Eosin Y (Sheehan \& Hrapchak 1980), and 2 adjacent sections from each individual were mounted on a glass microscope slide. Microscopy was used to sex each individual and to examine each testis section for the presence of oocytes. Ovaries were not examined in this study. When an oocyte was observed in either section from one individual, the total number of oocytes in that section was counted manually. In the case that there were oocytes in both sections, we only counted and measured oocytes in one section. The diameter of each oocyte was then measured in Image Pro Plus ${ }^{\circledR}$. In some sections, we observed hundreds or thousands of oocytes, and were unable to measure each one. When we observed $>100$ oocytes slide ${ }^{-1}$, we randomly selected $20 \%$ of the area of the gonadal section and measured the diameter of all oocytes in that area. Measurements were completed only for oocytes in which a nucleus was visible, to ensure accurate size measurement. Since many oocytes were not perfectly spherical due to histological processing, the maximum diameter was recorded. All measurements in Image-Pro Plus ${ }^{\circledR}$ were calibrated with a stage micrometer accurate to $10 \mu \mathrm{m}$.

\subsection{Statistics}

Differences in intersex prevalence between the 2 collection sites were compared using the Pearson's chi-squared test with Yates' continuity correction. The average oocyte diameter was calculated for each intersex individual and the mean of these averages was calculated for each population. Oocyte diameters are reported $\pm \mathrm{SD}$. Individuals with secondary oocytes were excluded from this analysis. Several linear regression models comparing the total length (TL) of all the males in the study as well as the oocyte count and diameter were fit between the populations to determine whether the condition presented differently in each locale.

\section{RESULTS}

Of the 2039 lionfish collected and sexed from North Carolina and the Bahamas, 1110 (54.4\%) were male and $929(45.6 \%)$ were female. In total, 884 of the males were stained and sectioned, and oocytes were observed in $129(14.59 \%)$ of these lionfish. While the TL of the males was significantly different between the 2 populations ( $p<0.001$; Fig. 1$)$, neither the percent prevalence of intersex $\left(\chi^{2}=1.39, \mathrm{df}=1, \mathrm{p}=\right.$ $0.238)$, the number of oocytes ind..$^{-1}(p=0.52$; Fig. 1$)$, nor the average size of primary growth oocytes (PGOs) $(\mathrm{p}=0.08)$ differed significantly between North Carolina and the Bahamas (Table 1). All

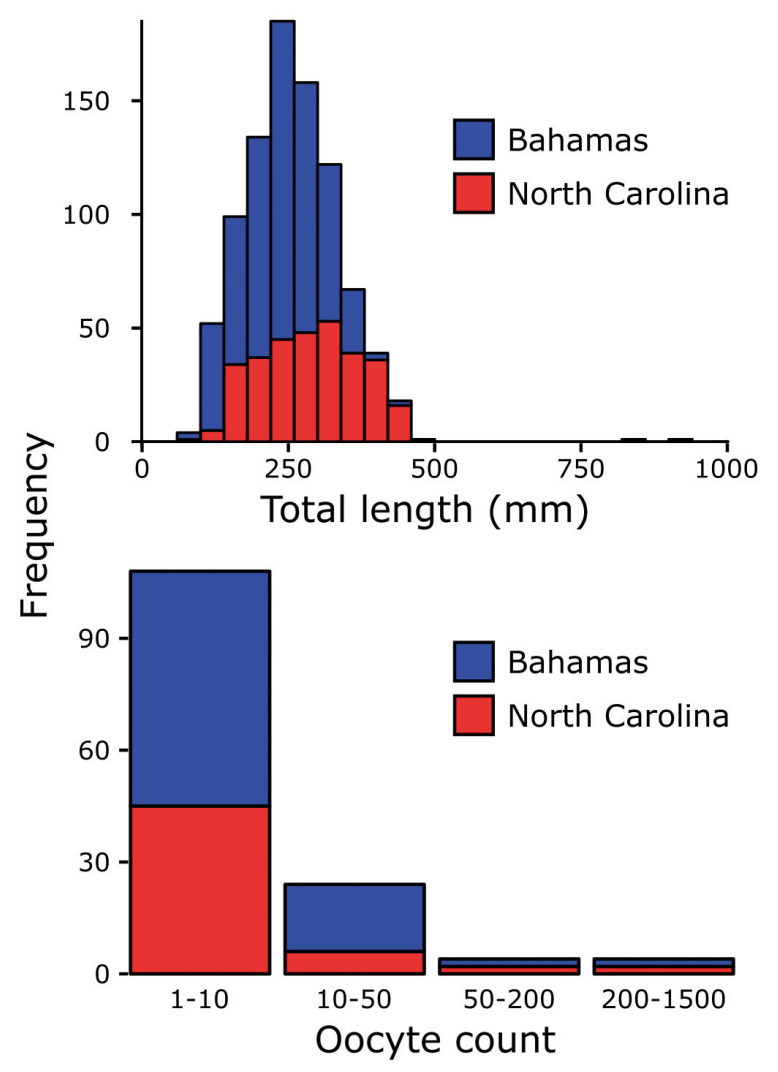

Fig. 1. Distributions of lionfish total length across all collected males and of oocyte counts within intersex males 
Table 1. Sampling statistics for both populations of lionfish. PGO: primary growth oocyte

\begin{tabular}{|lccccccc|}
\hline Location & $\begin{array}{c}\text { Females } \\
\text { collected }\end{array}$ & $\begin{array}{c}\text { Males } \\
\text { collected }\end{array}$ & $\begin{array}{c}\text { Average total } \\
\text { length of } \\
\text { males }(\mathrm{mm})\end{array}$ & $\begin{array}{c}\text { Testes } \\
\text { samples }\end{array}$ & $\begin{array}{c}\text { Intersex } \\
\text { males }\end{array}$ & $\begin{array}{c}\text { Prevalence } \\
(\%)\end{array}$ & $\begin{array}{c}\text { Average PGO } \\
\text { diameter } \\
( \pm \mathrm{SD})(\mu \mathrm{m})\end{array}$ \\
\hline North Carolina & 393 & 452 & 291 & 319 & 53 & 16.6 & $21 \pm 5$ \\
Bahamas & 536 & 658 & 239 & 565 & 76 & 13.5 & $24 \pm 8$ \\
Total & 929 & 1110 & 258 & 884 & 129 & 14.6 & $23 \pm 7$ \\
\hline
\end{tabular}

affected fish exhibited PGOs, while only 3 lionfish collected from 2 nearshore reefs in Nassau, Bahamas, exhibited secondary oocytes (SOs). Several fish without SOs displayed particularly high numbers (531292) of PGOs, each of which was collected from a different site. Due to the similar pathology of intersex between the 2 populations, we treated them as one group for all further analyses.

Testicular tissue containing only PGOs appeared normal, aside from the presence of oocytes (Fig. 2). Specifically, all stages of sperm development were observed within spermatocysts, and spermatozoa were in the lumens of the lobules and the sperm ducts. PGOs were consistent in form with chromatinnucleolar oocytes in female lionfish. Each PGO displayed a germinal vesicle with a single nucleolus surrounded by a simple follicular complex (Fig. 2B). Primary oocytes with no visible nucleoli were thought to be an artefact of histological processing, where the microtome blade did not cut through the center of the oocyte. In fish with no SOs (sensu Brown-Peterson et al. 2011), PGOs were found throughout the gonad and had a mean diameter of $22 \pm 7 \mu \mathrm{m}$.

Unlike the sections containing only primary oocytes, sections with SOs showed intermediate structures and gross morphology. These gonads were characterized by the formation of a central stroma (Fig. 2C) and peduncles attached to late-stage oocytes (Fig. 3B). The organization of the oocytes had early-stage oocytes clustered near the stroma and late SOs found outside the gonadal walls with all developmental stages of oocytes between (Fig. 2C). In addition, there were no apparent spermatocysts or lumens of the lobules as would be expected in healthy teste tissue. Despite this generally ovary-like organization, the tissue did not look like a typical ovary section (see Morris et al. 2011, Fogg et al. 2017). Although the fish were large (303-326 mm TL), and therefore would be expected to be fully sexually mature, each section had very few oocytes of any stage (Fig. 2C).

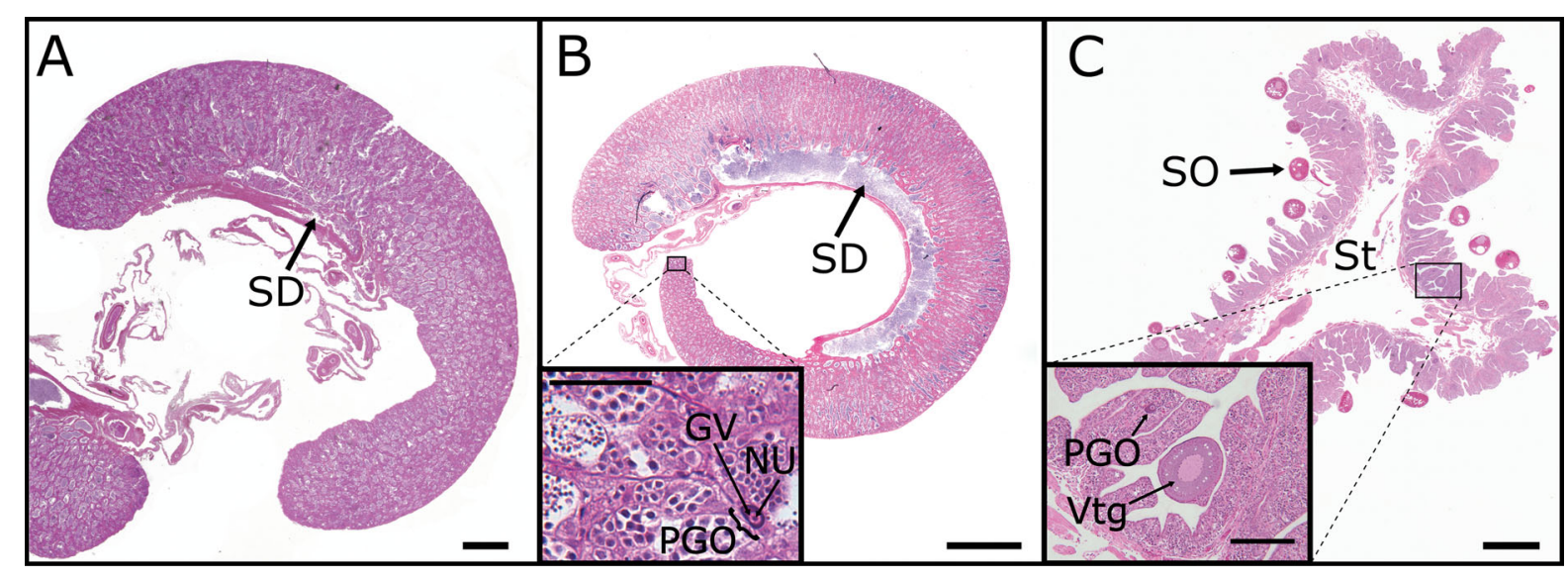

Fig. 2. Overall morphology and composition of healthy lionfish testis sections and those with mild intersex were similar; however a few individuals displayed very different gonadal morphology. (A) Testis from a healthy male lionfish with active spermatogenic tissue throughout, including spermatozoa, spermatagonia, and spermatocytes. A sperm duct (SD) is present, but no spermatozoa are visible within the structure. Scale bar: $500 \mu \mathrm{m}$. (B) Testis from a male displaying intersex with only primary growth oocytes (PGO). PGOs are interspersed throughout the tissue and have a nucleolus (NU) and a germinal vescicle (GV). The sperm duct and lumens of the lobules are full of spermatozoa. Additionally, spermatozoa and spermatocytes are visible in the inset. Scale bars: $1000 \mu \mathrm{m}$, inset $50 \mu \mathrm{m}$. (C) Intersex section with a central stroma (St) and stratification of oocyte size from primary (towards stroma) to secondary (towards periphery). SO: secondary oocyte. PGOs and a primary vitellogenic oocyte

(Vtg) shown in inset. Scale bars: $1000 \mu \mathrm{m}$, inset $200 \mu \mathrm{m}$ 


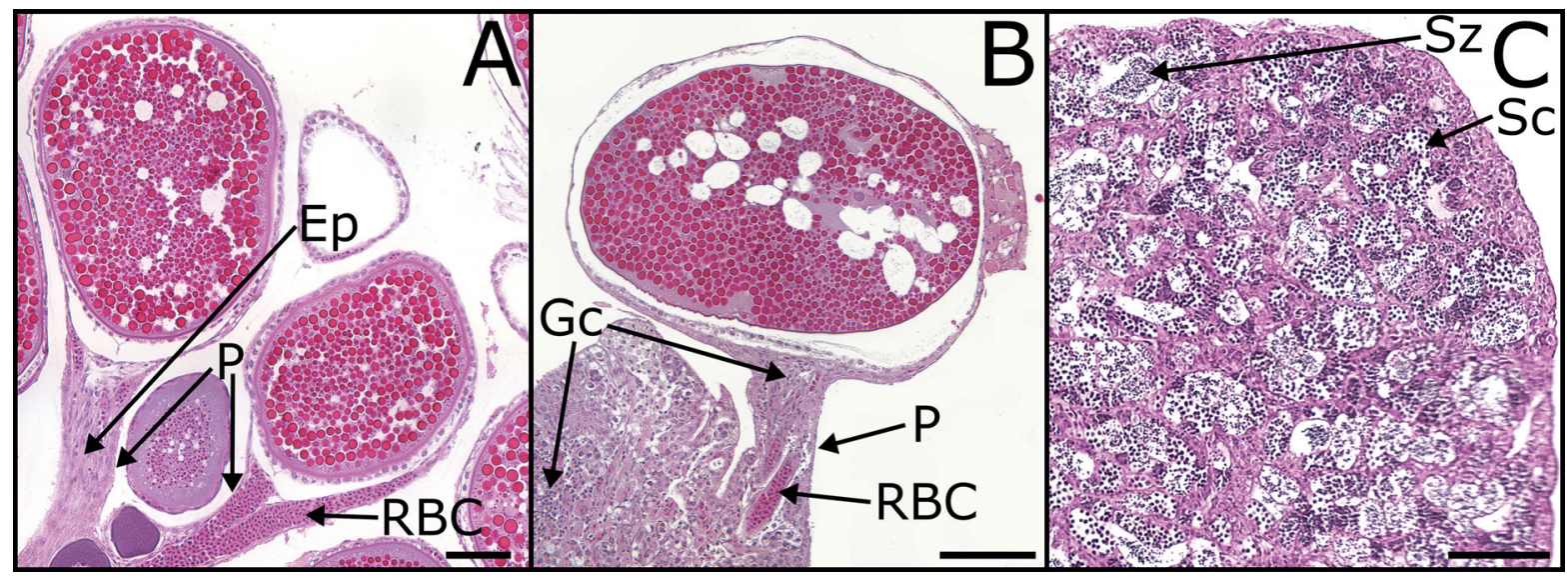

Fig. 3. Tissue of the anomalous intersex lionfish individuals is intermediate to ovaries and testes. (A) Several tertiary vitellogenic oocytes from a healthy ovary are suspended on highly vascularized peduncles (P) composed primarily of epithelial cells (Ep). Red blood cells (RBC) are visible in one of the peduncles. (B) A tertiary vitellogenic oocyte from an atypical intersex individual is attached to the gonad body via a vascularized peduncle similarly to the healthy ovary. However, unlike in the ovary, the peduncle seems to be composed of gametogenic tissue actively producing gametocytes (Gc). The gaps throughout the tissue are reminiscent of testis tissue. (C) Healthy testis tissue, arranged with spermatozoa (Sz) and spermatocytes (Sc) growing in separate spermatocysts. All scale bars: $100 \mu \mathrm{m}$

Instead, a vast majority of the tissue was producing early-stage gametes (as seen in Fig. 3B). It is also interesting to note that the peduncles appeared to be made of gametogenic tissue in the intersex individuals, while they are comprised primarily of epithelial cells in healthy ovaries (Fig. 3A). Finally, we note that these sections are inconsistent with immature ovaries since they have SOs and only a small amount of interstitial tissue.

The chromatin-nucleolar oocytes near the stroma of sections with SOs were similar to those in all the other specimens, showing a germinal vesicle with a single nucleolus surrounded by a follicular complex. These PGOs ranged in diameter from 33.2 to $58.8 \mu \mathrm{m}$. Late PGOs with multiple nucleoli around the edge of the germinal vesicle, perinucleolar oocytes, demonstrated that these oocytes were developing normally (Fig. 4A). Cortical alveoli-stage oocytes were characterized by a developed follicular complex, the presence of cortical alveoli, and a homogeneous nucleoplasm with many nucleoli around the edge (Fig. 4B). Vitellogenic-stage oocytes were observed to have nucleoli in the germinal vesicles, scattered lipid droplets, and were attached to the stroma by a peduncle (Figs. 2C, 3B \& 4C-D). Oocyte maturation was characterized by the migration and partial disintegration of the germinal vesicle and coalescence of lipid droplets. Some also appeared to have peduncle detachment points indicating near ovulation, however, many did not have any apparent peduncle. It is impossible to differentiate between detached oocytes and sections in which we simply missed the peduncle. The maximum observed secondary oocyte size was $422 \mu \mathrm{m}$.

\section{DISCUSSION}

Our results demonstrate that intersex is widely present in invasive lionfish from both North Carolina and the Bahamas. It is not known whether the cause of the condition is the same between the locations, but despite the geographic distance between them, the pathology of the disease was very similar in both sites. Therefore, we do not have any reason to believe that the cause of the condition differs between the sites, and we describe intersex collectively in all sampled individuals. Although we did not establish the cause of intersex in these fish, several recognized causes are possible in this system. These invasive populations are living well outside of their natural range and therefore might be subjected to physiological stressors whose effects could include causing intersex (Jobling \& Tyler 2003). Alternatively, the fish could be exposed to endocrine disrupting chemical (EDC) pollution. In medaka Oryzias latipes, EDC exposure at $3 \mathrm{~d}$ post-fertilization caused a higher prevalence of intersex later in life than exposure at any other life stage (Gray et al. 1999). Although these same results have not been demonstrated in a scorpaeniid fish, it demonstrates that environmental pollution may have the greatest impact on sexual devel- 


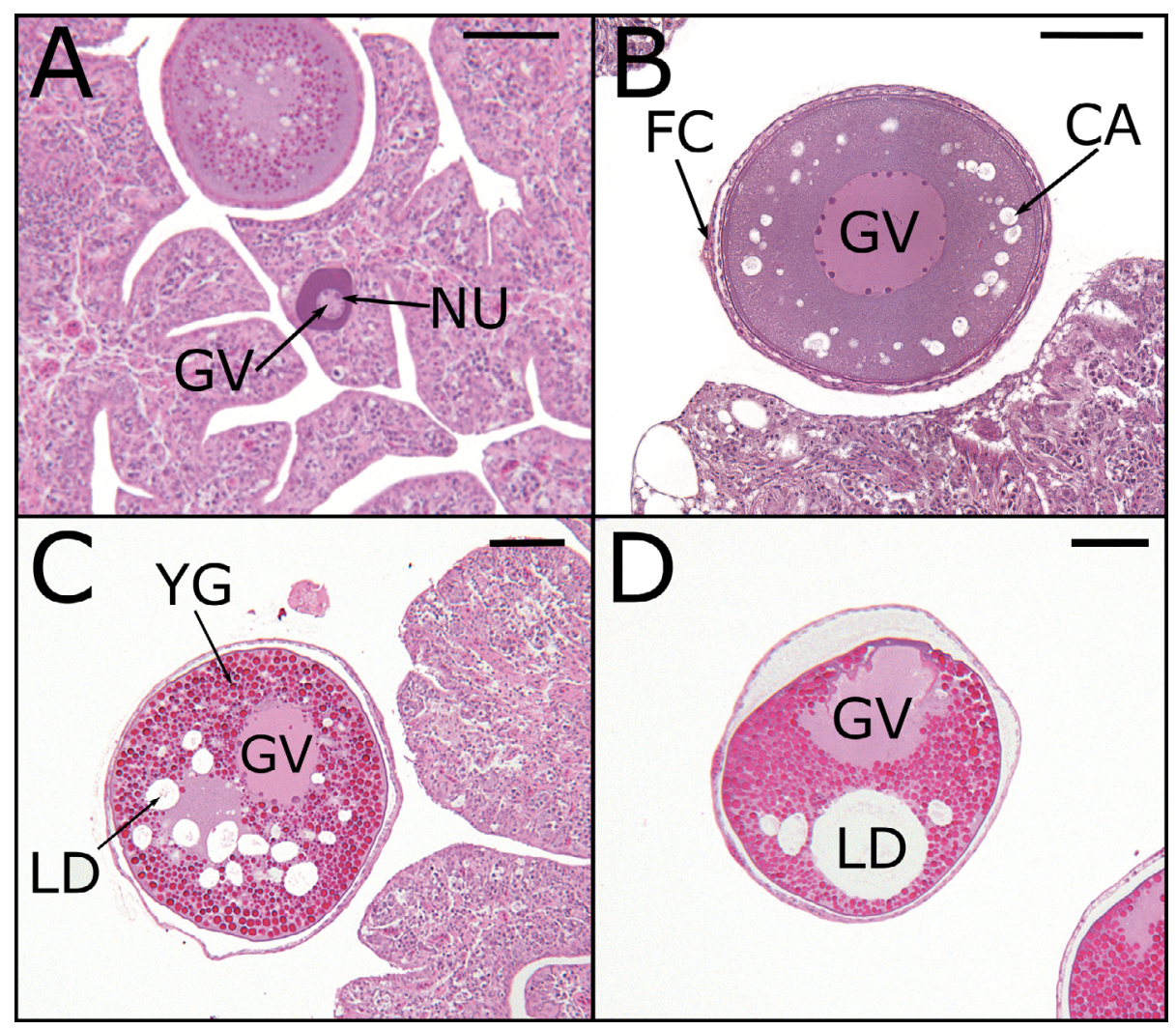

Fig. 4. Three of the intersex lionfish individuals displayed oocytes at all developmental stages. (A) Multiple nucleoli (NU) are arranged around the edge of the germinal vesicle (GV) in late primary growth oocytes. (B) Cortical alveoli oocytes present with a distinct follicular complex (FC), numerous cortical alveoli (CA), and a GV with homogeneous nucleoplasm containing nucleoli around the edge. (C) Vitellogenic oocytes have many lipid droplets (LD) and yolk granules (YG), while maintaining the presence of the germinal vesicle. (D) Coalescence of the lipid droplets as well as disintegration and migration of the germinal vesicle indicate that this vitellogenic oocyte has progressed to oocyte maturation. All scale bars: $100 \mu \mathrm{m}$

opment very early in a fish's life. Unfortunately, it is difficult to determine pollutant exposure in this species since lionfish are planktonic for the first $30 \mathrm{~d}$ post-fertilization (Ahrenholz \& Morris 2010). Without knowing where they drifted as embryos, it is almost impossible to address this hypothesis in wild populations. Finally, our findings could represent a natural prevalence of intersex in lionfish. Although there are reports of high natural levels of intersex (Grim et al. 2007), our findings are still significantly higher than the only other report of intersex in lionfish $(0.5 \%$, 1 of 212 ind.; Fogg et al. 2017). This suggests that we were not simply observing a natural occurrence of the disease.

The range of TL of sampled males was similar across both collection locations, although the means differed (Fig. 1). This large overlap further indicates that the 2 populations could be expected to show a similar range of phenotypes and did not need to be analyzed separately. Of the fish that were intersex, nearly all of them had fewer than 10 oocytes (Fig. 1).
Blazer et al. (2007) report that there is a high likelihood of failing to detect intersex in low severity individuals when only 2 sections are examined, as was the case in our study. Given that our median oocyte count was so low, our estimate of the prevalence likely represents a lower limit for the actual population value.

Oocytes within all intersex individuals were morphologically consistent with normal development in ovaries and with the one previous report of intersex in lionfish (Fogg et al. 2017). However, intersex oocytes were typically smaller than those of the corresponding developmental stage in healthy ovaries. While PGOs in female lionfish are reported to vary in diameter from 20-60 $\mu \mathrm{m}$ (Morris et al. 2011), PGOs from intersex males had a mean diameter of $22.7 \pm$ $7.3 \mu \mathrm{m}$. This was only true in fish lacking SOs; the PGOs in the 3 atypical intersex individuals spanned the same size range as in healthy ovaries. SOs in these individuals did not show the same correspondence to healthy females. Specifically, vitellogenic 
oocytes reached a maximum diameter of $422 \mu \mathrm{m}$, compared to a minimum of $500 \mu \mathrm{m}$ in females (Morris et al. 2011).

Although most of the intersex individuals displayed minor morphological changes, a few individuals were highly atypical compared to either typical ovaries or testes. Such cases have rarely been reported in the literature before, but were described in Jobling et al. (1998), Nolan et al. (2001), van Aerle et al. (2001), and Depiereux et al. (2014). In each of these studies, the atypical intersex was characterized by gonads that were composed of discrete sections of male and female tissue and produced oocytes. This differs from our observations, in which the entire gonad was homogenous and had ambiguous composition. All the tissue, including the oocyte peduncles, appeared to be made of gametogenic tissue. This omnipresence of gametogenic tissue is not observed in healthy females and is more similar to teste tissue (Fig. 3). Furthermore, gametes at a similar developmental stage seem to be highly clustered, which is also consistent with healthy spermatogenic tissue. However, spermatocytes and oocytes at such an early stage are indistinguishable via histology, so we cannot say whether the tissue is actively producing spermatocytes or whether the structure of the tissue is just similar to a typical teste. It is also hard to know what an ovary would look like if it had comparably few oocytes, since immature ovaries are composed largely of PGOs and interstitial tissue whereas mature ovarian biomass is dominated by oocytes, not connective tissue (Fogg et al. 2017). Although many features were inconsistent with female lionfish, the organization of oocytes throughout the gonad was consistent with normal ovary development. Because of this ambiguity, we cannot conclude whether these individuals are genetically male or female. However, the intersex morphology of these gonads is certainly novel, and we hope that future studies will shine more light on the cause and true nature of such individuals.

It is interesting to note that all 3 of the animals displaying more substantial intersex came from 2 nearby sites in the Bahamas, and that many fish only displaying PGOs were collected at the same sites ( $\mathrm{n}=$ 86 total from both sites). However, the fish that displayed greater than 50 primary oocytes but no morphological feminization or SOs came from multiple sites in both the Bahamas and North Carolina. At least within the more typical intersex fish, it seems as though the severity of the condition can vary greatly in any site. We also note that although we found many individuals displaying varying numbers of
PGOs as well as several intersex individuals with fully developed oocytes and altered morphology, we did not find any fish that were intermediate to these 2 pathologies. This stands in contrast to the other studies that found SOs, all of which characterized the severity of the condition on a continuous scale (Jobling et al. 1998, van Aerle et al. 2001, Depiereux et al. 2014).

Although many ecological efforts are aimed at preserving species, lionfish are the focus of eradication efforts in their invasive range. Unfortunately, it is unlikely that intersex would have a substantial effect on the reproductive output of the western Atlantic lionfish population. Although intersex was observed at a relatively high rate, most of these males had very few oocytes. Furthermore, the organization and spermatogenesis of the testicular tissue appeared to be unaffected in all males with only primary oocytes, no matter how many oocytes were observed. While the 3 anomalous individuals would be likely to experience more serious reproductive consequences, this level of severity is so rare that the effect on the population would be negligible.

This study represents the first substantial report of intersex in lionfish, the first report of widespread intersex in a reef fish, and several interesting cases of intermediate gonads in a gonochoristic species. Of particular note is the manner in which these gonads were organized, with teste-like gametogenic tissue comprising ovarian structures that are typically epithelial. We hope that our results will prove to be valuable in marine ecotoxicology as well as in efforts to control the spread of this damaging invasive species.

Acknowledgements. We thank the editor and 3 anonymous reviewers for their constructive and thorough comments. This work was supported by the NOAA National Ocean Service, National Centers for Coastal Ocean Science and the Five College Coastal and Marine Sciences Program. All applicable international, national, and/or institutional guidelines for the care and use of animals were followed, consistent with American Veterinary Medical Association (AVMA) guidelines.

\section{LITERATURE CITED}

Ahrenholz DW, Morris JA (2010) Larval duration of the lionfish, Pterois volitans along the Bahamian Archipelago. Environ Biol Fishes 88:305-309

Arukwe A (2001) Cellular and molecular responses to endocrine-modulators and the impact on fish reproduction. Mar Pollut Bull 42:643-655

Bahamonde PA, Munkittrick KR, Martyniuk CJ (2013) Intersex in teleost fish: Are we distinguishing endocrine disruption from natural phenomena? Gen Comp Endocrinol 192:25-35 
Blazer VS, Iwanowicz LR, Iwanowicz DD, Smith DR and others (2007) Intersex (testicular oocytes) in smallmouth bass from the Potomac River and selected nearby drainages. J Aquat Anim Health 19:242-253

Brown-Peterson NJ, Wyanski DM, Saborido-Rey F, Macewicz BJ, Lowerre-Barbieri SK (2011) A standardized terminology for describing reproductive development in fishes. Mar Coast Fish 3:52-70

* Depiereux S, Liagre M, Danis L, De Meulder B, Depiereux E, Segner H, Kestemont P (2014) Intersex occurrence in rainbow trout (Oncorhynchus mykiss) male fry chronically exposed to ethynylestradiol. PLOS ONE 9: e98531

Fogg AQ, Brown-Peterson NJ, Peterson MS (2017) Reproductive life history characteristics of invasive red lionfish (Pterois volitans) in the northern Gulf of Mexico. Bull Mar Sci 93:791-813

Gardner PG, Frazer TK, Jacoby CA, Yanong RPE (2015) Reproductive biology of invasive lionfish (Pterois spp.). Front Mar Sci 2:7

Gray MA, Metcalfe CD (1997) Induction of testis-ova in Japanese medaka (Oryzias latipes) exposed to $p$-nonylphenol. Environ Toxicol Chem 16:1082-1086

Gray MA, Niimi AJ, Metcalfe CD (1999) Factors affecting the development of testis-ova in medaka, Oryzias latipes, exposed to octylphenol. Environ Toxicol Chem 18: 1835-1842

Grim KC, Wolfe M, Hawkins W, Johnson R, Wolf J (2007) Intersex in Japanese medaka (Oryzias latipes) used as negative controls in toxicologic bioassays: a review of 54 cases from 41 studies. Environ Toxicol Chem 26: 1636-1643

Hare JA, Whitfield PE (2003) An integrated assessment of the introduction of lionfish (Pterois volitans/miles complex) to the Western Atlantic Ocean. NOAA Tech Memo NOS NCCOS 2

Imai S, Koyama J, Fujii K (2005) Effects of $17 \beta$-estradiol on the reproduction of Java-medaka (Oryzias javanicus), a new test fish species. Mar Pollut Bull 51:708-714

Jobling S, Tyler CR (2003) Endocrine disruption, parasites

Editorial responsibility: Helmut Segner,

Bern, Switzerland and pollutants in wild freshwater fish. Parasitology 126: S103-S107

Jobling S, Nolan M, Tyler CR, Brighty G, Sumpter JP (1998) Widespread sexual disruption in wild fish. Environ Sci Technol 32:2498-2506

Kavanagh RJ, Balch GC, Kiparissis Y, Niimi AJ, Sherry J, Tinson C, Metcalfe CD (2004) Endocrine disruption and altered gonadal development in white perch (Morone americana) from the lower Great Lakes Region. Environ Health Perspect 112:898-902

Metcalfe CD, Metcalfe TL, Kiparissis Y, Koenig BG and others (2001) Estrogenic potency of chemicals detected in sewage treatment plant effluents as determined by in vivo assays with Japanese medaka (Oryzias latipes). Environ Toxicol Chem 20:297-308

Morris JA Jr (ed) (2012) Invasive lionfish: a guide to control and management. Special Publication Series No. 1. Gulf and Caribbean Fisheries Institute, Marathon, FL

Morris JA Jr, Whitfield PE (2009) Biology, ecology, control and management of the invasive Indo-Pacific lionfish: an updated integrated assessment. NOAA Tech Memo NOS NCCOS 99

Morris JA Jr, Sullivan CV, Govoni JJ (2011) Oogenesis and spawn formation in the invasive lionfish, Pterois miles and Pterois volitans. Sci Mar 75:147-154

Nolan M, Jobling S, Brighty G, Sumpter JP, Tyler CR (2001) A histological description of intersexuality in the roach. J Fish Biol 58:160-176

* Ruiz-Carus R, Matheson RE, Roberts DE, Whitfield PE (2006) The western Pacific red lionfish, Pterois volitans (Scorpaenidae), in Florida: evidence for reproduction and parasitism in the first exotic marine fish established in state waters. Biol Conserv 128:384-390

Sheehan DC, Hrapchak BB (1980) Theory and practice of histotechnology. Mosby, St Louis, MO

* van Aerle R, Nolan TM, Jobling S, Christiansen LB, Sumpter JP, Tyler CR (2001) Sexual disruption in a second species of wild cyprinid fish (the gudgeon, Gobio gobio) in United Kingdom freshwaters. Environ Toxicol Chem 20:2841-2847

Submitted: February 21, 2018; Accepted: November 2, 2018 Proofs received from author(s): December 17, 2018 